\title{
Prevalence of 2 UGT1A1 Gene Variations Related to Gilbert's Syndrome in South of Iran: An Epidemiological, Clinical, and Genetic Study
}

\author{
Mohammad Reza Heydari, ${ }^{1}$ Majid Fardaei,,${ }^{2,}$ Mohammad Rahim Kadivar, ${ }^{3}$ Abbas Rezaianzadeh, \\ Mohammad Reza Panjehshahin, ${ }^{1}$ Zeinab Gholami Bardeji, ${ }^{5}$ Mohammad Reza Miri, ${ }^{6}$ and Jamileh
}

\author{
Saberzadeh ${ }^{6}$ \\ ${ }^{1}$ Department of Pharmacology, Medical School, Shiraz University of Medical Sciences, Shiraz, Iran \\ ${ }^{2}$ Department of Medical Genetic, Medical School, Shiraz University of Medical Sciences, Shiraz, Iran \\ ${ }^{3}$ Department of Pediatric, Namazi Hospital, Shiraz University of Medical Sciences, Shiraz, Iran \\ ${ }^{4}$ Department of Epidemiology, Shiraz University of Medical Sciences, Shiraz, Iran \\ ${ }^{5}$ Department of Radiology, Medical Imaging Research Center, Namazi Hospital, Shiraz University of Medical Sciences, Shiraz, Iran \\ ${ }^{6}$ Medical Biotechnology Department, School of Advanced Medical Sciences and Technology, Shiraz University of Medical Sciences, Shiraz, Iran
}

"Corresponding author: Majid Fardaei, Department of Medical Genetic, Medical School, Shiraz University of Medical Sciences, Zand Street, Postal code: 71348-53185, Shiraz, Iran. Tel: +98-7132349610, Fax: +98-7132349610, E-mail: mfardaei@sums.ac.ir

Received 2016 November 28; Revised 2017 January 13; Accepted 2017 February 01.

\begin{abstract}
Background: Gilbert's syndrome can present as a chronic or benign asymptomatic condition, characterized by a slight increase in the serum bilirubin level without any hemolysis. In 1995, a genetic variation, located in the TATA box of UGT1A1 gene promoter, was identified in patients with Gilbert's syndrome. Also, further analysis identified a new missense variation, Gly71Arg, within the codon region of UGT1A1 gene. Coincidence of TATA box and Gly71Arg variations and their relationship with clinical findings are mostly variable.

Objectives: The aim of this study was to determine TATA box and Gly71Arg variations of UGT1A1 gene and assess their effects on clinical findings in patients with Gilbert's syndrome in southern provinces of Iran.

Methods: In this cross sectional study, 213 unrelated infants and children, below 12 years, who were admitted to the pediatric ward of Namazi hospital, Shiraz, Iran, were enrolled from June 2015 to May 2016. Blood-extracted DNA was used for genotyping TATA box and Gly71Arg variations by sequencing. Further biochemical analyses were performed for each patient.

Results: About 78.9\% of the studied subjects had normal homozygous genotypes, and 21.1\% were heterozygous for the Gly71Arg variation. In total, $34 \%$ of the cases were normal in the promoter region (TA6/6), and 55\% were heterozygous with genotypes TA6/7, TA6/5, and TA 6/8. Three combinations of genotypes, ie, TA6/7-Gly/Gly, TA7/7-Gly/Gly, and TA7/7-Gly/Arg, showed significant differences in the serum total bilirubin level. Also, creatinine phosphokinase in TA6/7-Gly/Arg, TA7/7-Gly/Gly, and TA7/7-Gly/Arg had a significant increase.

Conclusions: The present findings showed that the TA7/7 promoter of UGT1A1 gene accounted for a considerable number of Gilbert's syndrome cases (11.3\%). The studied variations had a significant effect on creatine phosphokinase and serum total bilirubin levels.
\end{abstract}

Keywords: Bilirubin, Gilbert's Disease, TATA Box, Genetic Variation, Glucuronosyltransferase

\section{Background}

Gilbert's syndrome (GS), first described by Gilbert and Lereboullet, is an autosomal recessive disorder, caused by changes in uridine diphosphate (UDP) glucuronosyltransferase 1A1 (UGT1A1) gene (1). GS is characterized as a mild, unconjugated hyperbilirubinemia in the absence of hepatic disease and hemolysis (2). The main cause of increased serum bilirubin level in GS patients is the reduction of glucuronosyltransferase enzyme activity (3). In these patients, based on the genetic population makeup, UDP glucuronosyltransferase activity can be reduced by up to $30 \%$ of the normal level (2).

So far, researchers have performed comprehensive studies on different aspects of GS, thus leading to the better management and recognition of this condition (4). The main common genetic cause of GS is mutation in the TATA box of UGT1A1 gene promoter, which plays a regulatory role in gene transcription. It is well known that $6 \mathrm{TA}$ repeats (UGT1A1*1) in this region are normal, while presence of $7 \mathrm{TA}$ repeats $\left(U G T 1 A 1^{*} 2\right)$ reduces glucuronosyltransferase activity; other variations are not well specified $(5,6)$.

It is speculated that the enlarged TATA box sequence is less effective in binding regulatory agents, which control the transcription of UGT1A1 gene (7). Further studies revealed another cause of GS, ie, G> A variation at nucleotide 211 in exon 1, which results in the substitution of glycine

Copyright (c) 2017, Iranian Red Crescent Medical Journal. This is an open-access article distributed under the terms of the Creative Commons Attribution-NonCommercial 4.0 International License (http://creativecommons.org/licenses/by-nc/4.0/) which permits copy and redistribute the material just in noncommercial usages, provided the original work is properly cited. 
to arginine at codon 71 (Gly71Arg) of UGT1A1 protein (8). In fact, the incidence of hyperbilirubinemia in neonates with Gly71Arg missense variation has been reported to be nearly $30 \%$ higher than the normal population in different ethnicities $(9,10)$. So far, 113 variants of UGT1A gene have been identified, which can lead to a wide spectrum of conditions ranging from jaundice and very mild conditions to severe, lethal diseases (11).

GS may not require a special medical treatment as it has benign consequences $(12,13)$. Although the main feature of GS is an elevated unconjugated bilirubin level, metabolism of some drugs and xenobiotics may be also affected (14). Acetaminophen, ethinylestradiol, indinavir, and irinotecan clearance from the serum is reduced in GS due to deficiency in drug glucuronidation. Accordingly, considering drug accumulation in the serum, some researchers have suggested a GS diagnostic test before irinotecan prescription to prevent severe side-effects (1517).

Although all conducted studies have emphasized on the relationship between GS and increased bilirubin level, in the present study, in addition to confirming previous findings in this area, the relationship between GS and elevated creatine phosphokinase (CPK) level was analyzed. The present study aimed to determine 2 variations of UGT1A1 gene and assess their effects on clinical findings in patients with GS.

\section{Methods}

\subsection{Sample Collection}

The sample size for this cross sectional study was determined to be 197, based on the following formula and previous studies $(18,19)(P=0.09$ and $d=0.04)$ :

$$
\begin{aligned}
N & =(196)^{2} \frac{P(1-P)}{d^{2}} \\
& =197
\end{aligned}
$$

To achieve this sample size, the process of subject recruitment started from June 2015. Any unrelated infant or child (below 12 years), who was referred to the emergency ward of Namazi hospital, Shiraz, Iran and was transferred to the pediatric ward, was included in this study. In May 2016, a total of 215 subjects were recruited, although 2 cases were eliminated, based on the exclusion criteria. Residence in Fars province or southern provinces of Iran and willingness to participate in the study were among the inclusion criteria.

Whole blood samples $(1.5 \mathrm{~mL})$ were collected from each patient in Greiner Bio-One Hematology K3-EDTA Lavender Evacuated Tubes and kept at $-20^{\circ} \mathrm{C}$ until DNA extraction.

\subsection{Ethical Considerations}

Sample collection and subsequent analysis were performed after obtaining a written informed consent from each patient according to the Declaration of Helsinki. The study was approved by the Medical Ethics Committee on Human Research of Shiraz University of Medical Sciences (code number, IR.SUMS.rec.1394.S95).

\subsection{Inclusion and Exclusion Criteria}

The study population included children below 12 years, who were living in Fars province or southern provinces of Iran. On the other hand, all cases who used liver enzyme inducers, such as barbiturates, aminopyrine, phenylbutazone, orphenadrine, or 3, 4-benzpyrene, were excluded from the study (20). According to these criteria, among 215 included cases, 2 cases were eliminated.

\subsection{Demographic and Biochemical Information}

A demographic questionnaire (including name, gender, phone number, address, age, history of neonatal jaundice, parent's history of jaundice, and history of specific diseases) was completed for each subject. Liver function test (LFT), as well as CPK, lactate dehydrogenase (LDH), blood urea nitrogen (BUN), and creatinine ( $\mathrm{Cr}$ ) levels, was measured by MAN Co. kits with a CS-400 auto-chemistry analyzer (DIRUI Industrial Co., Ltd, Eastern China).

\subsection{Preparation of Genomic DNA}

Genomic DNA was extracted from the peripheral blood lymphocytes (100 - $200 \mu \mathrm{L})$ by the RIBO-prep nucleic acid extraction kit variant 100 (K2-9-Et-50-CE, Slovak Republic), according to the manufacturer's instructions. The concentration of the extracted genomic DNA was determined by measuring the ultraviolet absorbance at $260 \mathrm{~nm}$ with the NanoDrop Lite Spectrophotometer (Thermo Scientific, USA). About 70 - $110 \mathrm{ng}$ of the genomic DNA was used for polymerase chain reaction (PCR).

\subsubsection{PCR and DNA Sequencing}

The promoter and exon 1 regions of UGT1A1 gene were amplified, using in-house designed primers. Forward and reverse primers to amplify the TATA box promoter and exon 1 included 5'-TGAAATTCCAGCCAGTTCAA-3' and 5'-TTGAAGACGTACCCTGTGC-3', respectively. The reaction mixture $(25 \mu \mathrm{L})$ contained $1 \mu \mathrm{L}$ of genomic DNA, $1 \mu \mathrm{L}$ of each forward and reverse primer (10 pmol/reaction), $13 \mu \mathrm{L}$ of AMPLIQON TEMPase Hot start 2x Master Mix (CinnaGen Co., Iran), and $9 \mu \mathrm{L}$ of $\mathrm{ddH}_{2} \mathrm{O}$.

Briefly, PCR was performed by denaturation at $95^{\circ} \mathrm{C}$ for 15 minutes, followed by 35 cycles at $94^{\circ} \mathrm{C}$ for 40 seconds, $55^{\circ} \mathrm{C}$ for 40 seconds, and $72^{\circ} \mathrm{C}$ for 40 seconds, with a final 
synthesis at $72^{\circ} \mathrm{C}$ for 5 minutes. The amplified PCR products were sequenced by forward and reverse primers, using the Sanger method (bi-directional sequencing). Finally, the nucleotide sequences were analyzed by BioEdit software.

\subsection{Statistical Analysis}

For data management and further analysis, SPSS version 21 was used. Descriptive analysis was performed for determining the frequency. Also, t test, Chi square, Fisher's exact test, and one-way analysis of variance (ANOVA), followed by Duncan's and LSD multiple-range tests, were used for pairwise comparisons. P value $\leq 0.05$ was considered statistically significant. For data which were not normally distributed, we used nonparametric Kruskal-Wallis test, as well as Bonferroni correction test. In these tests, P value $\leq$ 0.003 was considered statistically significant.

\section{Results}

\subsection{Demographic Characteristics}

A total of 213 unrelated infants and children, below 12 years, were included in this study. The mean age of the subjects, including 123 males (57.75\%) and 90 females (42.25\%), was $5.69 \pm 3.4$ months. Among all cases, $25.3 \%(n=54)$ had a history of diseases. Overall, $61 \%(n=130)$ of the patients' parents were consanguineously married. The mean body mass index (BMI) of the subjects was $16.36 \pm 0.31 \mathrm{~kg} / \mathrm{m}^{2}$. Based on the findings, no relationship was found between these characteristics and the laboratory data. It should be also noted that all cases were from southern provinces of Iran.

\subsection{Analysis of UGT1A1 Variations}

In the evaluated population, 5 possible genotypes were identified, based on the amplification and sequencing of UGT1A1 gene promoter. These genotypes included common homozygous allele TA6/6, common heterozygous allele TA6/7, rare heterozygous alleles TA6/5 and TA6/8, and rare homozygous allele TA7/7. The minimum and maximum frequencies of alleles carrying TA variations were 0.5\% and 53.5\%, respectively (Table 1 ).

The genotype distribution of Gly71Arg variation among 213 Iranian children and neonates was determined as follows: Gly/Gly ( $\mathrm{n}=168,78.9 \%)$ and Gly/Arg $(\mathrm{n}=45,21.1 \%)$ (Table 1 and Figure 1 ). With respect to the coincidence of promoter TATA box and Gly71Arg variations, 8 genotypes were detected. TA6/7-Gly/Gly was recognized as the most frequent genotype (46.1\%), while TA6/8-Gly/Gly and TA6/5Gly/Gly were rare genotypes (0.5\%) (Table 2 ).

\subsection{Laboratory Parameters}

All the participants underwent LFT, CPK, LDH, BUN, and $\mathrm{Cr}$ tests. The results related to the association between laboratory tests and combined genotypes are presented in Tables 3 and 4. Among promoter and UGT1A1*6 variation groups, there was a statistically significant difference in the serum total bilirubin (STB) level between TA7/7-Gly/Gly ( $\mathrm{P}=0.017), \mathrm{TA7} / 7-\mathrm{Gly} / \operatorname{Arg}(\mathrm{P}<0.001)$, and TA6/7-Gly/Gly $(\mathrm{P}$ $=0.009)$ genotypes. Also, a statistically significant difference was found regarding CPK level between TA7/7-Gly/Gly $(\mathrm{P}=0.034), \mathrm{TA} 7 / 7-\mathrm{Gly} / \operatorname{Arg}(\mathrm{P}=0.022)$, and TA6/7-Gly/Arg $(\mathrm{P}$ $=0.012)$ genotypes, compared to other groups. However, other liver laboratory tests showed no significant difference between the genotype groups.

Other than LDH test, gender had no effects on the results of laboratory tests in different genotype groups. Statistical analysis of UGT1A1*6 variations showed that homozygosity of Gly71Arg alone had no impact on the increase in STB or CPK level. The variation in LDH was significant in heterozygous Gly71Arg, while it was insignificant in combination with other variations in the promoter region. Also, we found no significant difference in STB level between children with and without a history of neonatal jaundice ( $0.53 \pm 0.4 ; \mathrm{P}=0.9$ ). Also, age and other demographic factors had no effects on liver laboratory test results.

\section{Discussion}

Although GS is known as a benign condition, it is of clinical importance due to its effects on the patient's liver enzyme profile. Clinical and epidemiological findings about GS in different ethnical groups can help researchers, pharmacists, and physicians introduce more effective medications. The prevalence of UGT1A1 gene polymorphisms in the promoter and exon 1(Gly71Arg) regions has been separately reported in only a limited number of cases $(21,22)$. The present study revealed the coincidence of these 2 polymorphisms and the clinical manifestations in the Iranian population for the first time.

In this regard, Hemmati et al. (23) determined the prevalence of GS, using rifampin test in Fars province, south of Iran. They reported an incidence rate of $19.1 \%$ in both genders for GS in the general population. The results of their study showed that the prevalence of GS in males (25.6\%) was higher than females (12.8\%), which is inconsistent with the present findings (14.3\% in males and 9\% in females); also, the overall prevalence was much lower in the present study (11.3\%). This discrepancy could be due to differences in the methods applied in these studies. 
Table 1. Distribution of Promoter TATA Box and Gly71Arg Variants Based on Age and Gender

\begin{tabular}{|c|c|c|c|c|c|c|c|}
\hline \multirow[b]{3}{*}{ Gender } & \multicolumn{7}{|c|}{ Genotype Frequency (\%) } \\
\hline & \multicolumn{5}{|c|}{ Promoter TATA box } & \multicolumn{2}{|c|}{ Gly/Arg } \\
\hline & TA6/6 & TA6/7 & TA6/8 & TA6/5 & TA7/7 & Gly/Gly & Gly/Arg \\
\hline Male & $40(32.8)$ & $70(56.6)$ & $1(0.8)$ & $1(0.8)$ & $11(9)$ & $96(78.7)$ & $26(21.3)$ \\
\hline Female & $33(36.3)$ & $45(49.4)$ & $0.0(0.0)$ & $0.0(0.0)$ & $13(14.3)$ & $72(79.1)$ & $19(20.9)$ \\
\hline Total (\%) & $73(34.2)$ & $114(53.5)$ & $1(0.5)$ & $1(0.5)$ & $24(11.3)$ & $168(78.9)$ & $45(21.1)$ \\
\hline $\operatorname{Age}^{a}$ & $37.7 \pm 42.9$ & $51.3 \pm 47.0$ & $12.0 \pm 0.0$ & $144.0 \pm 0.0$ & $49.9 \pm 44.88$ & $47.5 \pm 46.38$ & $42.0 \pm 44.6$ \\
\hline
\end{tabular}

${ }^{\mathrm{a}}$ Age in months (mean $\pm \mathrm{SD}$ ).
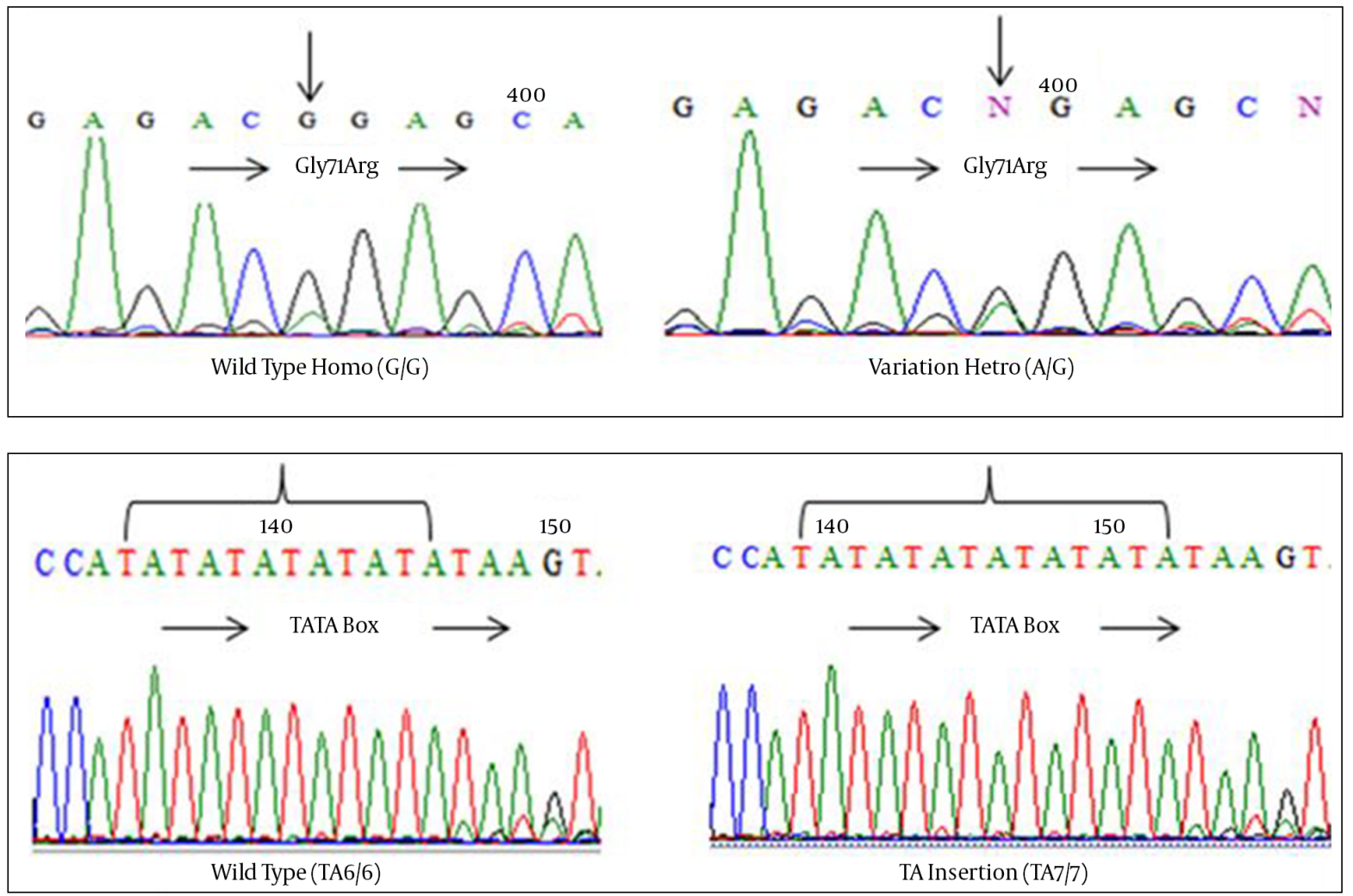

Figure 1. Sequencing chromatogram of UGT1A1 gene in the c.211G > A site. Arrows indicate the nucleotide substitution position.

By using the restriction fragment length polymorphism (RFLP) method, Dastgerdy et al. found that the frequency of Gly71Arg variation (homozygous and heterozygous) was $30.4 \%$, which was higher than the rate reported in the present study (21.1\%). The high frequency might be attributed to the low specificity and sensitivity of RLFP method (24). Also, similar to studies by Ergin and Kaveh, we found that homozygous TA7/7 genotype is associated with increased STB level in case of additional TA insertion in the promoter $(21,25)$.

In the Malay population, Yossef et al. observed that the prevalence of homozygous TA7/7, heterozygous TA6/7, and heterozygous Gly71Arg (Gly/Arg) mutations was 7\%, 18\%, and 5.5\%, respectively. In the present study, similar to the mentioned research, homozygous Gly71Arg (Arg/Arg) was not detected. However, we observed a higher frequency of heterozygous TA7/6 (55.4\%) than homozygous TA7/7 (11.3\%), compared to the study by Yusoff et al. (43.5\% and 9.9\%, re- 
Table 2. Prevalence of Promoter TATA Box and Gly71Arg Variants Based on Gender in Southern Provinces of Iran

\begin{tabular}{|c|c|c|c|c|c|c|c|}
\hline \multirow{3}{*}{ Genotype Ggroups TATA } & \multirow{3}{*}{ Genotype Groups Gly71Arg } & \multicolumn{4}{|c|}{ Gender } & \multirow{2}{*}{\multicolumn{2}{|c|}{ Total }} \\
\hline & & \multicolumn{2}{|c|}{ Female } & \multicolumn{2}{|c|}{ Male } & & \\
\hline & & Frequency & $\%$ & Frequency & $\%$ & Frequency & $\%$ \\
\hline TA6/6 & Gly/Gly & 29 & 13.62 & 30 & 14.08 & 59 & 27.70 \\
\hline TA6/6 & Gly/Arg & 4 & 1.88 & 10 & 4.69 & 14 & 6.57 \\
\hline TA6/7 & Gly/Gly & 38 & 17.84 & 60 & 28.17 & 98 & 46.01 \\
\hline TA6/7 & Gly/Arg & 6 & 2.82 & 10 & 4.69 & 16 & 7.51 \\
\hline TA7/7 & Gly/Gly & 4 & 1.88 & 5 & 2.35 & 9 & 4.23 \\
\hline TA7/7 & Gly/Arg & 9 & 4.23 & 6 & 2.82 & 15 & 7.04 \\
\hline TA6/5 & Gly/Gly & 0 & 0 & 1 & 0.47 & 1 & 0.47 \\
\hline TA6/8 & Gly/Gly & 0 & 0 & 1 & 0.47 & 1 & 0.47 \\
\hline Total & & 90 & 42.25 & 123 & 57.75 & 213 & 100 \\
\hline
\end{tabular}

Table 3. The Results of Laboratory Tests (Mean \& IQR) in the Genotype Groups ${ }^{\mathrm{a}}$

\begin{tabular}{|c|c|c|c|c|c|c|c|c|c|c|c|c|c|c|c|c|}
\hline \multirow[t]{4}{*}{ Laboratory test (unit) } & \multicolumn{16}{|c|}{ Genotype Groups } \\
\hline & \multirow{2}{*}{\multicolumn{2}{|c|}{$\begin{array}{c}\text { TA6/6 } \\
\text { Gly/Gly }\end{array}$}} & \multirow{2}{*}{\multicolumn{2}{|c|}{$\begin{array}{c}\text { TA6/6 } \\
\text { Gly/Arg }\end{array}$}} & \multirow{2}{*}{\multicolumn{2}{|c|}{$\begin{array}{c}\text { TA6/7 } \\
\text { Gly/Gly }\end{array}$}} & \multirow{2}{*}{\multicolumn{2}{|c|}{$\begin{array}{c}\text { TA6/7 } \\
\text { Gly/Arg }\end{array}$}} & \multirow{2}{*}{\multicolumn{2}{|c|}{$\begin{array}{c}\text { TA7/7 } \\
\text { Gly/Gly }\end{array}$}} & \multirow{2}{*}{\multicolumn{2}{|c|}{$\begin{array}{c}\text { TA7/7 } \\
\text { Gly/Arg }\end{array}$}} & \multirow{2}{*}{\multicolumn{2}{|c|}{$\begin{array}{c}\text { TA6/5 } \\
\text { Gly/Gly }\end{array}$}} & \multirow{2}{*}{\multicolumn{2}{|c|}{$\begin{array}{c}\text { TA6/8 } \\
\text { Gly/Gly }\end{array}$}} \\
\hline & & & & & & & & & & & & & & & & \\
\hline & Median & $\mathrm{IQR}^{\mathrm{b}}$ & Median & IQR & Median & IQR & Median & IQR & Median & IQR & Median & IQR & Median & IQR & Median & IQR \\
\hline $\operatorname{ALP}(\mathbf{U} / \mathbf{L})$ & 300.0 & 171.8 & 275.5 & 213.0 & 300.0 & 116.5 & 318.0 & 232.0 & 369.0 & 51.9 & 314.0 & 60.5 & 756.0 & 0.0 & 422.0 & 0.0 \\
\hline $\operatorname{AST}(\mathbf{U} / \mathbf{L})$ & 41.0 & 31.5 & 36.0 & 48.0 & 38.0 & 38.5 & 47.0 & 49.5 & 69.0 & 108.5 & 53.0 & 94.3 & 47.0 & 0.0 & 19.0 & 0.0 \\
\hline $\operatorname{ALT}(\mathbf{U} / \mathbf{L})$ & 24.0 & 30.0 & 21.5 & 24.3 & 19.5 & 47.1 & 24.0 & 55.0 & 20.0 & 114 & 19.0 & 50.0 & 23.0 & 0.0 & 8.0 & 0.0 \\
\hline $\operatorname{LDH}(\mathbf{U} / \mathbf{L})$ & 490.0 & 897.0 & 580.0 & 665.5 & 522.0 & 366.5 & 895.5 & 1571.3 & 1586 & 4049 & 478.0 & 238.4 & 48.0 & 0.0 & 427.0 & 0.0 \\
\hline BUN $(\mathbf{m g} / \mathbf{d L})$ & 9 & 9.5 & 8.0 & 6.8 & 12.0 & 8.0 & 11.0 & 6.3 & 8.0 & 9.5 & 11.5 & 6.8 & 7.0 & 0.0 & 6.0 & 0.0 \\
\hline $\operatorname{Cr}(\mathrm{mg} / \mathrm{dL})$ & 0.5 & 0.30 & 0.5 & 0.35 & 0.5 & 0.2 & 0.6 & .35 & 0.5 & 0.3 & 0.5 & 0.2 & 4.1 & 0.0 & 0.2 & 0.0 \\
\hline
\end{tabular}

Table 4. The Results of Laboratory Tests (mean \pm SD) in the Genotype Groups

\begin{tabular}{|c|c|c|c|c|c|c|c|c|}
\hline \multirow{3}{*}{$\begin{array}{l}\text { Laboratory } \\
\text { test (unit) }\end{array}$} & \multicolumn{8}{|c|}{ Genotype Groups } \\
\hline & TA6/6 & TA6/6 & TA6/7 & TA6/7 & TA7/7 & TA7/7 & TA6/5 & TA6/8 \\
\hline & Gly/Gly & Gly/Arg & Gly/Gly & Gly/Arg & Gly/Gly & Gly/Arg & Gly/Gly & Gly/Gly \\
\hline $\mathrm{STB}(\mathrm{mg} / \mathrm{dL})$ & $0.40 \pm 0.20$ & $0.41 \pm 0.18$ & $0.54 \pm 0.21^{\mathrm{a}}$ & $0.46 \pm 0.32$ & $0.85 \pm 0.12^{\mathrm{a}}$ & $0.87 \pm 0.21^{\mathrm{a}}$ & $0.40 \pm 0.00$ & $0.20 \pm 0.00$ \\
\hline $\operatorname{CPK}(\mathbf{U} / \mathbf{L})$ & $358.20 \pm 219.2$ & $132.00 \pm 80.0$ & $\begin{array}{c}204.58 \pm \\
194.30\end{array}$ & $\begin{array}{c}444.40 \pm \\
134.14^{\mathrm{a}}\end{array}$ & $\begin{array}{c}469.00 \pm \\
83.20^{\mathrm{a}}\end{array}$ & $452.50 \pm 9.7^{\mathrm{a}}$ & $127.00 \pm 0.00$ & $114.00 \pm 0.00$ \\
\hline
\end{tabular}

Abbreviations: BUN, blood urea nitrogen; CPK, creatine phosphokinase; $\mathrm{Cr}$, creatinine; STB, serum total bilirubin

${ }^{\mathrm{a}}$ The difference between wild type and other genotypes is significant $(\mathrm{P} \leq 0.05)$.

spectively) $(26,27)$. Also, Nettles et al. showed that $11 \%$ of the Swiss population had GS, and the polymorphism had a significant correlation with the total bilirubin level. The present findings were in line with the results reported by Nettles et al.; nevertheless, they did not study other liver enzymes (28).
The results of the present study showed that Gly71Arg variation had no independent effects on STB level; this indicates that this variation only affects neonatal jaundice, not bilirubin level in the postneonatal period $(9,10)$. We found that none of the 2 variations (TATA and Gly71Arg) alone had a significant effect on CPK level, while in combi- 
nation with some other genotypes, an increase in CPK level was revealed.

In some studies, the prevalence of TA7/7 and Gly71Arg variations has been reported to be $3-19 \%$ and $20-60 \%$, respectively (29-33). One of the important findings of the present study was identifying 2 rare TA6/8 and TA6/5 genotypes with no significant increase in STB level. These genotypes have been previously reported in African populations (34). In the current study, we also showed a significant increase in the CPK level in GS cases, which has not been previously reported; nevertheless, for further clarification, more studies are required.

The strengths of the present study include the use of sequencing method, detection of 2 rare mutations (TA6/8 and TA6/5), and the relationship between GS and CPK level. On the other hand, the shortcoming of this study was the limited sample size due to restricted sources. In conclusion, the present study showed that the prevalence of GS in south of Iran was nearly similar to other populations.

\section{Acknowledgments}

This manuscript was extracted from a PhD thesis by Mohammad Reza Heydari and was funded by the ViceChancellor for Research Affairs of Shiraz University of Medical Sciences, Shiraz, Iran (grant number, 94-7475).

\section{Footnote}

Conflicts of Interest: The authors declare no conflicts of interest.

\section{References}

1. Song J, Sun M, Li J, Zhou D, Wu X. Three-dimensional polyacrylamide gel-based DNA microarray method effectively identifies UDPglucuronosyltransferase $1 \mathrm{~A} 1$ gene polymorphisms for the correct diagnosis of Gilbert's syndrome. Int J Mol Med. 2016;37(3):575-80. doi: 10.3892/ijmm.2016.2453. [PubMed: 26781906].

2. D'Angelo R, Rinaldi C, Donato L, Nicocia G, Sidoti A. The combination of new missense mutation with [A(TA)7TAA] dinucleotide repeat in UGT1A1 gene promoter causes Gilbert's syndrome. Ann Clin Lab Sci. 2015;45(2):202-5. [PubMed: 25887876].

3. Shiu TY, Huang HH, Lin HH, Shih YL, Chu HC, Chang WK, et al. Restriction fragment length polymorphism effectively identifies exon $1 \mathrm{mu}-$ tation of UGT1A1 gene in patients with Gilbert's Syndrome. Liver Int. 2015;35(8):2050-6. doi: 10.111//liv.12785. [PubMed: 25611851].

4. Bosma PJ. Inherited disorders of bilirubin metabolism. J Hepatol. 2003;38(1):107-17. [PubMed: 12480568].

5. Sticova E, Jirsa M. New insights in bilirubin metabolism and their clinical implications. World J Gastroenterol. 2013;19(38):6398-407. doi: 10.3748/wjg.v19.i38.6398. [PubMed: 24151358].

6. Chen Z, Su D, Ai L, Jiang X, Wu C, Xu Q, et al. UGT1A1 sequence variants associated with risk of adult hyperbilirubinemia: a quantitative analysis. Gene. 2014;552(1):32-8. doi: 10.1016/j.gene.2014.09.009. [PubMed: 25200497].
7. Carpenter SL, Lieff S, Howard TA, Eggleston B, Ware RE. UGT1A1 promoter polymorphisms and the development of hyperbilirubinemia and gallbladder disease in children with sickle cell anemia Am J Hematol. 2008;83(10):800-3. doi: 10.1002/ajh.21264. [PubMed: 18756540].

8. Takeuchi K, Kobayashi Y, Tamaki S, Ishihara T, Maruo Y, Araki J, et al. Genetic polymorphisms of bilirubin uridine diphosphateglucuronosyltransferase gene in Japanese patients with CriglerNajjar syndrome or Gilbert's syndrome as well as in healthy Japanese subjects. J Gastroenterol Hepatol. 2004;19(9):1023-8. doi: 10.1111/j.14401746.2004.03370.x. [PubMed: 15304120].

9. Kilic I, Koseler A, Cakaloz I, Atalay E. Screening for G71R mutation of the UDP-glucuronosyltransferase 1 (UGT1A1) gene in neonates with pathologic and prolonged hyperbilirubinemia in Turkey. Int J Clin Pharmacol Ther. 2010;48(8):504-8. [PubMed: 20650040].

10. Yamamoto A, Nishio H, Waku S, Yokoyama N, Yonetani M, Uetani Y, et al. Gly71Arg mutation of the bilirubin UDP-glucuronosyltransferase $1 \mathrm{~A} 1$ gene is associated with neonatal hyperbilirubinemia in the Japanese population. Kobe J Med Sci. 2002;48(3-4):73-7. [PubMed: 12502904].

11. Strassburg CP. Pharmacogenetics of Gilbert's syndrome. Pharmacogenomics. 2008;9(6):703-15. doi: 10.2217/14622416.9.6.703. [PubMed 18518849].

12. Kundur AR, Singh I, Bulmer AC. Bilirubin, platelet activation and heart disease: a missing link to cardiovascular protection in Gilbert's syndrome?. Atherosclerosis. 2015;239(1):73-84. doi: 10.1016/j.atherosclerosis.2014.12.042. [PubMed: 25576848].

13. Yuce S, Cure E, Cicek Y, Cumhur Cure M, Yilmaz A, Kizilkaya B. Evaluation of aortic stiffness in Gilbert syndrome patients: a protective effect of elevated bilirubin levels. Turk Kardiyol Dern Ars. 2015;43(7):599606. doi: 10.5543/tkda.2015.44457. [PubMed: 26536984].

14. Tukey RH, Strassburg CP. Human UDP-glucuronosyltransferases: metabolism, expression, and disease. Annu Rev Pharmacol Toxicol. 2000;40:581-616. doi: 10.1146/annurev.pharmtox.40.1.581. [PubMed: 10836148].

15. Martinez-Balibrea E, Abad A, Valladares M, Martinez-Villacampa M, Aranda E, Marcuello E, et al. Pharmacogenetic analysis of TS and UGT1A polymorphisms predictive for response and toxicity in Spanish patients with advanced colorectal cancer treated with first-line irinotecan and 5-fluorouracil. Journal of clinical oncology : official journal of the American Society of Clinical Oncology 2009;27(15_suppl):4066.

16. Rasool A, Sabir S, Ashlaq M, Farooq U, Khan MZ, Khan FY. Gilbert's Syndrome-a Concealed Adversity for Physicians and Surgeons.JAyub Med Coll Abbottabad. 2015;27(3):707-10. [PubMed: 26721045].

17. Teh LK, Hashim H, Zakaria ZA, Salleh MZ. Polymorphisms of UGT1A1*6, UGT1A1*27 \& UGT1A1*28 in three major ethnic groups from Malaysia. Indian J Med Res. 2012;136(2):249-59. [PubMed: 22960892].

18. Culley CL, Kiang TK, Gilchrist SE, Ensom MH. Effect of the UGT1A1*28 allele on unconjugated hyperbilirubinemia in HIV-positive patients receiving Atazanavir: a systematic review. Ann Pharmacother 2013;47(4):561-72. doi: 10.1345/aph.1R550. [PubMed: 23548653].

19. Alaee E. The Association between Prolonged Jaundice and UGT1A1 Gene Polymorphism (G71R) in Gilbert's Syndrome.J Clin Diagnos Res. 2016;10(11):GC05-GC8. doi: 10.7860/jcdr/2016/19004.8810.

20. Lynch T, Price A. The effect of cytochrome P450 metabolism on drug response, interactions, and adverse effects. Am Fam Physician. 2007;76(3):391-6. [PubMed: 17708140].

21. Kaveh M, Esmailnia T, Nayeri F, Nili F, Davari Tanha F, Ghajarzdeh M. UDP-glucuronosyltransferase promoter polymorphism in Iranian neonates with idiopathic hyperbilirubinemia. Acta Med Iran. 2013;51(11):789-92. [PubMed: 24390949]. 
22. Shakibi R, Kamalidehghan B, Ahmadipour F, Meng GY, Houshmand M. Prevalence of the UGT1A1*6 (c.211G>A) Polymorphism and Prediction of Irinotecan Toxicity in Iranian Populations of Different Ethnicities. Chemotherapy. 2014;60(5-6):279-87. doi: 10.1159/000376568. [PubMed: 25967674].

23. Hemmati F, Saki F, Saki N, Haghighat M. Gilbert syndrome in Iran, Fars Province. Ann Saudi Med. 2010;30(1):84. doi: 10.4103/0256-4947.59376. [PubMed: 20103965].

24. Dastgerdy E, Mamori G, Afshari J, Saeedi R, Shahbazi F, Shirazi M. Association of G71R Mutation of the UGT1A1 Gen with Neonatal Hyper Bilirubinemia in the Iranian Population. J Family Reproduct Health. 2012;6(1):35-8.

25. Ergin H, Bican M, Atalay OE. A causal relationship between UDPglucuronosyltransferase $1 \mathrm{~A} 1$ promoter polymorphism and idiopathic hyperbilirubinemia in Turkish newborns. Turk JPediatr. 2010;52(1):2834. [PubMed: 20402064].

26. Yusoff S, Van Rostenberghe H, Yusoff NM, Talib NA, Ramli N, Ismail NZ, et al. Frequencies of A(TA)7TAA, G71R, and G493R mutations of the UGT1A1 gene in the Malaysian population. Biol Neonate. 2006;89(3):171-6. doi:10.1159/000088844. [PubMed: 16210851].

27. Yusoff S, Takeuchi A, Ashi C, Tsukada M, Ma'amor NH, Zilfalil BA, et al. A polymorphic mutation, C.-3279T $>$ G, in the UGT1A1 promoter is a risk factor for neonatal jaundice in the Malay population. Pediatr Res. 2010;67(4):401-6. doi: 10.1203/PDR.ob013e3181d22f78. [PubMed: 20057336].

28. Nettles RE, Child MJ, Bertz RJ, Schnittman S. Gilbert syndrome and the development of antiretroviral therapy-associated hyperbilirubine- mia: genetic screening is unnecessary. J Infect Dis. 2006;193(11):1611-2. doi: 10.1086/503814. [PubMed: 16652295] author reply 1611-2.

29. Huang CS, Luo GA, Huang ML, Yu SC, Yang SS. Variations of the bilirubin uridine-diphosphoglucuronosyl transferase $1 \mathrm{~A} 1$ gene in healthy Taiwanese. Pharmacogenetics. 2000;10(6):539-44. [PubMed: 10975608].

30. Hsieh SY, Wu YH, Lin DY, Chu CM, Wu M, Liaw YF. Correlation of mutational analysis to clinical features in Taiwanese patients with Gilbert's syndrome. Am J Gastroenterol. 2001;96(4):1188-93. doi: 10.1111/j.15720241.2001.03699.x. [PubMed: 11316168].

31. Cheng J, Li L. [Molecular genetic basis of Gilbert's syndrome]. Zhonghua Gan Zang Bing Za Zhi. 2002;10(5):395-7. [PubMed:12392633].

32. Prachukthum S, Gamnarai P, Kangsadalampai S. Association between UGT 1A1 Gly71Arg (G71R) polymorphism and neonatal hyperbilirubinemia. J Med Assoc Thai. 2012;95 Suppl 1:S13-7. [PubMed: 23964438].

33. Canu G, Minucci A, Zuppi C, Capoluongo E. Gilbert and Crigler Najjar syndromes: an update of the UDP-glucuronosyltransferase 1A1 (UGT1A1) gene mutation database. Blood Cells Mol Dis. 2013;50(4):27380. doi: 10.1016/j.bcmd.2013.01.003. [PubMed: 23403257].

34. Li Y, Buckley D, Wang S, Klaassen CD, Zhong XB. Genetic polymorphisms in the TATA box and upstream phenobarbital-responsive enhancer module of the UGT1A1 promoter have combined effects on UDP-glucuronosyltransferase $1 \mathrm{~A} 1$ transcription mediated by constitutive androstane receptor, pregnane $\mathrm{X}$ receptor, or glucocorticoid receptor in human liver. Drug Metab Dispos. 2009;37(9):1978-86. doi: 10.1124/dmd.109.027409. [PubMed:19541828]. 